\title{
Lockdown ou vigilância participativa em saúde? Lições da Covid-19
}

Heleno Rodrigues Corrêa Filho',2, Ana Maria Segall-Corrêa3

DOI: $10.1590 / 0103-1104202012400$

ESTA EDIC̣ÃO DA REVISTA 'SAÚDE EM DEBATE' TRAZ contribuições para entender o mundo da saúde coletiva no momento crítico da pandemia de Coronavírus de 2020 (Severe Acute Respiratory Syndrome Coronavirus 2 - Sars-Cov-2), em que doença em decorrência desse vírus foi chamada de Covid-19. Em editorial anterior, a 'Saúde em Debate' expressou a previsão de que o sucesso do modelo chinês traria críticas inevitáveis para o modelo ocidental de mitigação e ação estatal vertical sem participação popular direta'.

Na segunda quinzena do mês de março de 2020, discutia-se no Brasil o fechamento indiscriminado das cidades (Lockdown) em oposição à experiência chinesa e coreana de vigilância epidemiológica pela mobilização popular com organização e informação pela base, fechamento seletivo e manutenção dos serviços essenciais de saúde, alimentação e sobrevivência.

A China venceu. No dia 3 de março de 2020, o governo chinês divulgou o primeiro boletim com nenhum caso novo de contágio pelo Coronavírus. No mesmo dia, a Itália anunciou a morte de mais de 600 pessoas, caminhando para o pico da epidemia estendida a todo o país depois do início na região da Lombardia, em torno da cidade de Milão.

Vários filmes feitos na China durante as ações de vigilância e controle revelaram que entrar e sair de condomínios, metrô, ônibus, locais de compra em Wuhan eram monitorados por membros do Partido Comunista Chinês e membros de Comitês Populares Locais. Esses comitês agiam como autoridades locais sob comando central definindo autorizações para sair para compras e contatos de estrita necessidade. Lembrando que necessidade ou serviço essencial é um conceito de classe segundo o qual o que é pouco para uma minoria é demais para muitos.

O controle de saída, trajeto e chegada foi feito na China utilizando aplicativos de redes sociais como 'WeChat', leitura de códigos de identificação padrão 'QR' por telefones celulares, centralização da informação e análise. O serviço estatal chinês forneceu infraestrutura de big data e computação para coleta, armazenamento, processamento e análise de informação visando ao controle da epidemia.

Se uma pessoa de Wuhan demonstrasse estar contagiada com sintomas ou sinais após ter andado em um vagão específico do metrô ou feito compras em supermercado, ela seria identificada quanto ao horário, trajeto, contatos e pessoas próximas a serem convocadas para exames e vigilância. Nem George Orwell imaginou um grande irmão tão presente com uma estrutura capilarizada para controlar pessoas e portadores de um vírus letal.

No mesmo período, a mortalidade na Coreia foi de 7,9 para mil $(0,79 \%)$ e acometeu
1 Centro Brasileiro de Estudos de Saúde (Cebes)

- Rio de Janeiro (RJ), Brasil. helenocorrea@uol.com.br

2 Universidade de Brasília (UnB) - Brasília (DF) Brasil.

3 Fundação Oswaldo Cruz (Fiocruz) - Brasília (DF), Brasil. 
principalmente idosos e grupos conglomerados em casas de abrigo de idosos. Na Itália, a mortalidade chegou acima de $9 \%$ e passou a matar bebês. Os gráficos ascendentes dos casos e mortalidade nos países da Europa e no Brasil fizeram prever que aqui haveria maior chance de reproduzir o modelo Italiano de disseminação da Covid-192.

A semelhança do Brasil com a Itália vem da implantação do modelo neoliberal destruindo aparatos públicos de serviços e vigilância em saúde na Itália após 2010. Qual a origem da tragédia italiana do Coronavírus 3,4? Em 2020, a Itália completou dez anos de cortes orçamentários. Estima-se que esse país tinha um deficit de 56 mil médicos e 50 mil enfermeiros. Ademais, entre 2015 e 2020, foram fechados 758 estabelecimentos italianos de saúde entre clínicas, policlínicas, centros de saúde e hospitais. Essa demolição do aparato público da atenção e da vigilância à saúde na Itália decorreu das práticas denominadas de 'austeridade' fiscal e orçamentária dos estados exigidas pela 'Troika' BCE-CEE-FMI (Banco Central Europeu, Comissão Econômica Europeia e o Fundo Monetário Internacional) que exigiram dos governos que reservassem a maior parte do orçamento público para financiar juros bancários e dívidas públicas e limitaram investimentos, serviços públicos e direitos de seguridade social.

A 'austeridade' que fechou o aparato público de saúde italiano foi semelhante à que passou a ser aplicada no Brasil a partir da falência de governo de coalizão (2010-2015), do golpe de estado jurídico e parlamentar (2016) e da eleição fraudulenta da ultradireita em 2018.

Programas ultraliberais semelhantes ocorreram na mesma época no Chile, no Peru, na Argentina, no Paraguai, no Equador, na Colômbia e na Bolívia, forçados pela pressão de sanções financeiras e diplomáticas internacionais, por campanhas de propaganda de mídia nas eleições, por golpes parlamentares ou pela chamada 'guerra híbrida' derrubando governos eleitos.

A pandemia pelo Sars-Cov-2 ou simplesmente o 'novo' Coronavírus da Síndrome de Angústia Respiratória Grave em 2019 aplainou a agressão drástica do modelo ultraliberal e agudizou a crise de acumulação de capital de forma a obrigar verdadeiro retrocesso da implantação dos 'estados austeros' de países como Reino Unido, Alemanha e França.

A Covid-19 acelerou providências europeias das medidas de salvamento de pobres, de transferência de renda a trabalhadores informais e empreendedores individuais, de doentes, idosos e crianças. Governos ultraliberais que defendiam que cada pessoa devia salvar-se a si passaram a distribuir renda para evitar morte por fome e doenças agudas e uma onda de saques ao comércio.

O governo dos EUA pressionou o Brasil na direção de manter a política ultraliberal enquanto modificava drasticamente sua política interna de Renda Mínima Cidadã, prometendo distribuir renda mensal mínima a todos os pobres estadunidenses durante a pandemia. Esse movimento político paradoxal chegou ao Brasil em convulsão no pico ascendente da pandemia com 400 mil casos no mundo, e 2.200 no Brasil (25/03/2020)2.

Havia e há pessoas na Internet defendendo o fechamento de fronteiras com deportação de viajantes que cheguem procedentes de área epidêmica. É desumano, cruel e epidemiologicamente ineficaz. Fechar fronteiras é ineficaz e autoritário. Serve a interesses políticos e econômicos. Sabemos que fascismo não impede a migração de bactérias, vírus, agentes tóxicos, contrabando e autoritarismo. Muito pelo contrário. O que deve ser feito é contratar pessoal capacitado para a vigilância em saúde e aumentar a participação popular 'direta' no direito de notificar, acompanhar a investigação e saber do desfecho dos casos. Acolher, tratar se necessário, notificar, investigar e jamais fechar fronteiras.

Restrição de viagens é política que exige controle de saída e de chegada. Deve ser feita com acompanhamento de necessidades planejadas. Pessoas com necessidade estrita de viajar 
em missão de estado, casos de falecimento e necessidades logísticas de comércio das atividades consideradas essenciais viajariam sabendo que, ao sair e chegar, passarão por controle de sinais e sintomas. Em caso de contato com o público, aceitam exames de triagem, se necessário, ficam em quarentena período máximo de incubação - 14 dias. Em circunstâncias controladas, só viajariam as pessoas em situação de busca de repatriação, aquelas em retorno ao país de origem, pessoas em busca de ações de cooperação internacional, estudo, migração e trabalho nas atividades também consideradas essenciais.

A Itália fez, no início da pandemia, um vaivém na política de distanciamento social4. Inicialmente, preferiu fechar os cidadãos em seus velhos burgos, pequenas cidades do Norte. Depois, resolveu isolar gente idosa e pobre para, posteriormente, entender que devia parar o País, permitindo, apenas, que as pessoas pudessem sair de casa por necessidade de comida e remédios. Na sequência, liberaram saídas e chegadas sem as restrições seletivas anteriores, para depois voltar outra vez às recomendações de distanciamento social. Uma coisa é dizer aos cidadãos que não saiam de casa durante 15 dias ou 20 dias e pedir que só circulem os materiais de alimentos e saúde. Outra coisa - ineficaz - é fechar cidades, prender migrantes e votar leis em segredo.

O modelo de controle social trabalhado por estatísticos e estudiosos de ciências da computação tem como ponto de partida a situação atual graduando diferentes níveis de eficácia do 'distanciamento social' ou do 'fique em casa se não quiser matar os outros ou ficar doente'.

O Brasil buscou convencer a população a não sair de casa. Pode ser que tenhamos sucesso em mudar o modelo e reduzir a velocidade da epidemia com proteção e 'achatamento da subida da curva'. O povo saberá entender se conseguiremos um resultado que nos aproxime mais da China e da Coreia do Sul e nos distancie do que aconteceu na Itália. Desejamos que a população pobre e trabalhadora não tenha de pagar pelo risco em ônibus e metrô lotados para servir à classe que pode romantizar a quarentena.

O distanciamento social e a testagem universal de contatos assintomáticos são as explicações do sucesso da Coreia do Sul em bloquear o aparecimento de casos novos e reduzir a mortalidade a quase cem vezes menos que a Itália.

Não adianta testar os níveis de IGM cinco dias depois de contatos suspeitos, sinais ou sintomas. É necessário teste rápido para portadores de partículas virais. O Brasil tem capacidade científica e tecnológica para fabricar kits diagnósticos. A Universidade Federal da Bahia e a Fundação Oswaldo Cruz desenvolveram kits em bancada de laboratório que não encontraram financiamento para a produção em plantas industriais. Faltou financiamento público por causa da 'austera' Emenda Constitucional $95^{5}$.

O sucesso da testagem universal já mobilizou inclusive os sanitaristas estadunidenses. A lista de internet dedicada à saúde pública denominada 'spiritof1848' defende a testagem universal nos EUA desde o final do mês de fevereiro de 2020 e o uso de máscaras faciais por pessoas portadoras do vírus ou doentes, evitando a disseminação para os $86 \%$ que serão assintomáticos (IC 95\%:[82\%-90\%]. A testagem universal permitiu na Coreia a busca e o isolamento dos assintomáticos positivos que são responsáveis por $55 \%$ da transmissão a casos novos (IC 95\%:[46\%-62\%] $)^{6-8}$. O que fez diferença foi isolar assintomáticos positivos. Além disso, atuaram os deuses da higiene - a água e o sabão.

A Coreia do Sul demonstrou criatividade com improvisação de máscaras para evitar contato humano com aerossóis de saliva e secreções humanas nos transportes públicos, mesmo com lotação reduzida. Na falta de produção industrial suficiente, usaram de tudo, desde meias-calças, pedaços de pano; retalhos de papel toalha, até copos de sutiãs amarrados no rosto. Virou piada internacional, mas funcionou. 
Em março de 2020, o Brasil ainda não tem um plano de mobilização e contingência para o distanciamento social e medidas de proteção coletiva e individual. Só com a Renda Mínima Cidadã poderia impedir a morte econômica da economia popular, a fome e a violência. Se nada for feito, os que não pegarem o Coronavírus vão pegar o 'guedesvírus' da falência, pobreza e falta de dinheiro para o aluguel, comida, luz, água, e tudo o que os ultraliberais privatizaram ou querem privatizar.

Apesar de o Brasil não ter modelo epidemiológico sanitário de controle, seja vertical, seja participativo, o País tem um conjunto de leis epidemiológicas autoritárias, que permitem ao governo federal aplicar medidas draconianas sem consultar e sem permitir ação de defesa dos interesses regionais ou locais?.

As melhores listas de necessidades essenciais e direitos da população trabalhadora sob quarentena e distanciamento social apareceram no manifesto das dez centrais sindicais brasileira e nas ' 16 perguntas das quebradas' publicadas pelo movimento das periferias urbanas ${ }^{10,11}$.

O Centro Brasileiro de Estudos de Saúde (Cebes) tem pautado sua ação de estudos e intercâmbio científico translacional entre os setores saúde, economia, direito, educação popular, e outros, com a interface formalizada nos fóruns de instituições como o Conselho Nacional de Saúde e as Frentes Nacionais criadas para a luta pela saúde e pela vida ${ }^{12,13}$.

As discussões nas diversas instâncias do Cebes e o conteúdo de sua revista 'Saúde em Debate' visam denunciar que a estratégia de mitigar para aguardar a imunização do 'rebanho' (imunidade de grupo) demonstrou-se ineficaz no Irã e na Itália. O custo de vidas humanas foi devido à altíssima taxa de reprodução (Rzero ou Ro) que levou a casos graves de bebês, crianças e jovens, além dos adultos idosos, com doenças concomitantes. Essa experiência não existia em janeiro por causa da baixa taxa de gravidade e proporção de assintomáticos, que era desconhecida em janeiro de 2020.

Os equipamentos de proteção individual demonstraram ser inúteis ou exigir várias camadas de proteção, o que os tornam inviáveis para uso na rede de atenção primária, pelo alto custo com descarte e limpeza, e indisponibilidade consequente ao volume de demanda com o número muito alto de casos. A extensão dessa demanda não era igualmente conhecida em janeiro de 2020 e tornou-se realidade concreta após o Coronavírus chegar ao Oriente Médio e Europa, em março do mesmo ano. O impacto disso foi a mortalidade altíssima de enfermeiros, auxiliares e médicos na Itália, chegando a prejudicar o atendimento de hospitais desaparelhados e sem pessoal, com adoecimento e morte de alto número dos profissionais de saúde.

Depois do conhecimento sobre a velocidade de reprodução $(\mathrm{Ro}=2,5)$, a alta taxa de assintomáticos transmissores (86\%), a persistência do vírus por até vários dias nos móveis, resíduos de hospital e nos objetos de uso individual e comunitário ('fômites' no dialeto sanitário), a incapacidade de reverter o quadro inflamatório agudo nos pacientes graves que são internados em Unidade de Tratamento Intensivo (UTI), mesmo com ventilação mecânica por até 20 dias consecutivos, mudaram o panorama na Europa. Tornaram igualmente insustentável a estratégia de Trump e Bolsonaro de deixar morrer muita gente para não paralisar a economia.

Denunciamos também como criminosa a estratégia de liberar comércio e atividades não essenciais, colocando em risco a população trabalhadora, na expectativa que a epidemia seja extinta e admitindo o aumento da mortalidade de muita gente pobre, da periferia, que não terá acesso aos meios que possam salvar suas vidas, como o acesso à UTI dos poucos hospitais que estarão aparelhados.

A estratégia da supressão planejada se impôs depois do conhecimento científico divulgado sobre a experiência da China, da Coréia do Sul, do Irã, da Itália, da Alemanha e do Reino Unido. O modelo adotado nos EUA, que mesmo lá sofre muita resistência, é um modelo assassino do 
imperialismo colonialista que impõe medidas de mitigação com liberação comercial e bancária. O governo brasileiro busca imitar essas estratégias desde o início do ano de 2020. Se aqui vencer a estratégia de 'liberar geral', saberemos que a implicação será a de mandar o povão morrer para que a economia, os investidores e financistas lucrem, como sempre acontece.

\section{Colaboradores}

Corrêa Filho HR (0000-0001-8056-8824)* é responsável pela elaboração do manuscrito. Segall-Corrêa AM (0000-0003-0140-064X)* contribuiu para a revisão do manuscrito.

\section{Referências}

1. Corrêa Filho HR. A utopia do debate democrático na vigilância em saúde. Saúde debate [internet]. 2020 [acesso em 2020 fev 19]; 43(123)979-81. Disponível em: https://doi.org/10.1590/0103-1104201912300.

2. The Center for Systems Science and Engineering (CSSE) at JHU. 2019-NCov Global Cases By Johns Hopkins CSSE - Online Accrual [Electronic Digital Media]. Baltimore - MD - USA: Johns Hopkins Whiting School of Engineering at JHU; 2020. [acesso em 2020 fev 4]. Disponível em: https://gisanddata.maps.arcgis.com/apps/opsdashboard/index. html\#/bda7594740fd40299423467b48e9ecf6.

3. Nogueira K, Ruivo E, Nogueira P, et al. Em fevereiro, quando contava 17 mortos, a Itália "protegeu a economia" e cancelou isolamento. Hoje são 6820. Diário do Centro do Mundo [internet]. 2020. [acesso em 2020 mar 26]. Disponível em: https://www.diariodocentrodomundo.com.br/em-fevereiro-quando-contava-17-mortos-a-italia-protegeu-a-economia-e-cancelou-isolamento-hoje-sao-6-820/.
4. Cimini F. Coronavírus: os 15 dias de brigas políticas que selaram o desfecho trágico da Itália. The Intercept Brasil [internet]. 2020. [acesso em 2020 mar 26]. Disponível em: https://theintercept. com/2020/03/24/coronavirus-poltica-italia/.

5. Brasil. Casa Civil. Emenda Constitucional $\mathrm{n}^{\mathrm{o}}$ 95, de 15 de dezembro de 2016 - Altera o Ato das Disposições Constitucionais Transitórias, para instituir o Novo Regime Fiscal, e dá outras providências, CLIV. Diário Oficial da União. 16 Dez 2016. [acesso em 2020 mar 26]. Disponível em: http:// pesquisa.in.gov.br/imprensa/jsp/visualiza/index.js p?data $=16 / 12 / 2016 \&$ jornal=1\&pagina=2\&totalArqui $\operatorname{vos}=368$.

6. Li R, Pei S, Chen B, et al. Substantial undocumented infection facilitates the rapid dissemination of novel coronavirus (SARS-CoV2). Science. 2020. [acesso em 2020 mar 26]. Disponível em: https://static. poder360.com.br/2020/03/science-estudo-coronavirus-contagio-documentacao-16-mar-2020.pdf.
*Orcid (Open Researcher and Contributor ID). 
7. Silva AAM. Sobre a possibilidade de interrupção da epidemia pelo coronavírus (COVID-19) com base nas melhores evidências científicas disponíveis. Rev. bras. epidemiol. [internet]. 2020 [acesso em 2020 mar 26]; 23. Disponível em: http://www. scielo.br/scielo.php?script=sci_arttext\&pid=S1415$-790 \times 2020000100100$.

8. Silva AAM. Sobre a importância da ampliação da capacidade de testagem dos sintomáticos para a contenção da epidemia pela COVID-19 no Brasil. Agência Bori [internet]. [acesso em 2020 mar 26]. Disponível em: https://abori.com.br/artigos/sobre-a-importancia-da-ampliacao-da-capacidade-de-testagem-dos-sintomaticos-para-a-contencao-da-epidemia-pela-covid-19-no-brasil/.

9. Corrêa Filho HR. Comentário à Lei do Coronavirus 2019: Uma lei autoritária sem garantias de cidadania. CEBES Portal Eletronico [internet]. [acesso em 2020 mar 26]. Disponível em: http:// cebes.org.br/2020/02/comentario-a-lei-do-coronavirus-2019-uma-lei-autoritaria-sem-garantias-de-cidadania/.

10. Borges T. Coronavírus e as quebradas: 16 perguntas ainda sem resposta sobre impacto da pandemia nas periferias. Periferia em Movimento - Informação dos extremos ao centro [internet]. [acesso em 2020 mar 26]. Disponível em: https://periferiaemmovimento.com.br/coronavirus-e-as-quebradas-16-perguntas-ainda-sem-resposta-sobre-impacto-da-pandemia-nas-periferias/.

11. Central Única dos Trabalhadores. Medidas de proteção à vida, à saúde, ao emprego e à renda dos trabalhadores e trabalhadoras. [internet]. [acesso em 2020 mar 26]. Disponível em: https://www.cut.org. $\mathrm{br} /$ noticias/coronavirus-cut-e-centrais-vao-exigir-medidas-de-protecao-ao-emprego-e-a-renda$-0 \mathrm{~d} 5 \mathrm{~d}$.

12. Centro Brasileiro de Estudos de Saúde. Cebes e a Frente Ampla em Defesa da Saúde dos Trabalhadores apoia, endossa e recomenda o posicionamento do MPT sobre a pandemia do COVID-19. [internet]. [acesso em 2020 mar 26]. Disponível em: http://cebes.org.br/2020/03/cebes-e-a-frente-ampla-em-defesa-da-saude-dos-trabalhadores-apoia-endossa-e-recomenda-o-posicionamento-do-mpt-sobre-a-pandemia-do-covid-19/.

13. Athaide C. Propostas de medidas para reduzir os impactos da pandemia de Covid19 nos territórios das favelas brasileiras - \#Afavelacontraovirus. CUFA - Central Única de Favelas [internet]. [acesso em 2020 mar 26]. Disponível em: https://www.cufa. org.br/noticia.php?n=MjYx. 